Case Report

\title{
Acute Airway Obstruction and Cardiopulmonary Arrest due to Tracheomalacia Caused by Megaesophagus Compression Secondary to Achalasia
}

\author{
Mickael Aubignat $\mathbb{D}^{\mathrm{D}},{ }^{1}$ Pierre-Alexandre Roger, ${ }^{2}$ Amandine Dernoncourt, ${ }^{1}$ Valery Salle, ${ }^{1}$ \\ Amar Smail, ${ }^{1}$ Clement Gourguechon, ${ }^{1}$ Jean Schmidt, ${ }^{1}$ and Pierre Duhaut ${ }^{1}$ \\ ${ }^{1}$ Department of Internal Medicine, Amiens University Hospital, France \\ ${ }^{2}$ Department of Respiratory Diseases and Intensive Care Unit, Amiens University Hospital, France \\ Correspondence should be addressed to Mickael Aubignat; aubignat.mickael@chu-amiens.fr
}

Received 29 January 2020; Accepted 27 April 2020; Published 9 May 2020

Academic Editor: Akif Turna

Copyright (c) 2020 Mickael Aubignat et al. This is an open access article distributed under the Creative Commons Attribution License, which permits unrestricted use, distribution, and reproduction in any medium, provided the original work is properly cited.

\begin{abstract}
We report the case of an 80-year-old woman who presented one episode of cardiopulmonary arrest and two episodes of acute airway obstruction. We found in this patient the presence of tracheomalacia caused by megaesophagus compression secondary to achalasia probably responsible for episodes of acute airway obstruction and cardiopulmonary arrest.
\end{abstract}

\section{Introduction}

Tracheomalacia (TM) is still an underdiagnosed disease but probably not a rare disease. In TM, we can find a reduction and/or an atrophy of longitudinal elastic fibers of the pars membranacea or impaired cartilage integrity. Prevalence in adults is unknown but is estimated between $12.7 \%$ and $44 \%$ from studies in selected populations [1,2]. Bronchoscopy remains the golden standard for diagnosis of TM. It allows visualization of dynamic expiratory collapse $[3,4]$.

Achalasia (AL) is a neurodegenerative motility disorder of the esophagus that results in abnormal peristalsis and loss of lower esophageal sphincter function, especially during swallowing $[5,6]$. Incidence is still rare, approximately 1.6 per $100,000[7,8]$. Modalities utilized most frequently for diagnosis include endoscopy, radiographic studies, and manometry. Esophageal manometry remains the golden standard for diagnosis of AL with findings of aperistalsis and failure of relaxation of the lower esophageal sphincter $[9,10]$.

We report the case of an 80-year-old woman who presented one episode of cardiopulmonary arrest and two episodes of acute airway obstruction. We found in this patient the presence of TM caused by megaesophagus compression secondary to achalasia probably responsible for episodes of acute airway obstruction and cardiopulmonary arrest.

\section{Case Presentation}

An 80 -year-old woman $(46 \mathrm{~kg}, 154 \mathrm{~cm})$ was transported to our intensive care unit intubated and ventilated with recovery of spontaneous circulation after cardiopulmonary arrest (no-flow 15 minutes, low-flow 10 minutes). She reported dyspnea and syncope in her toilets following a pushing effort. She had no previous history of respiratory or cardiac disease. She is followed for giant cell arteritis and myelodysplasia without other medical history.

Initial evolution was rapidly favorable, and the patient regained consciousness without sequelae. Etiologic assessment carried out initially did not explain this episode of cardiopulmonary arrest. CT-chest performed initially when the patient was intubated found a megaesophagus but no tracheal compression (Figure 1).

A week later, the patient presented an episode of acute respiratory distress with bradycardia during a meal. Faced 


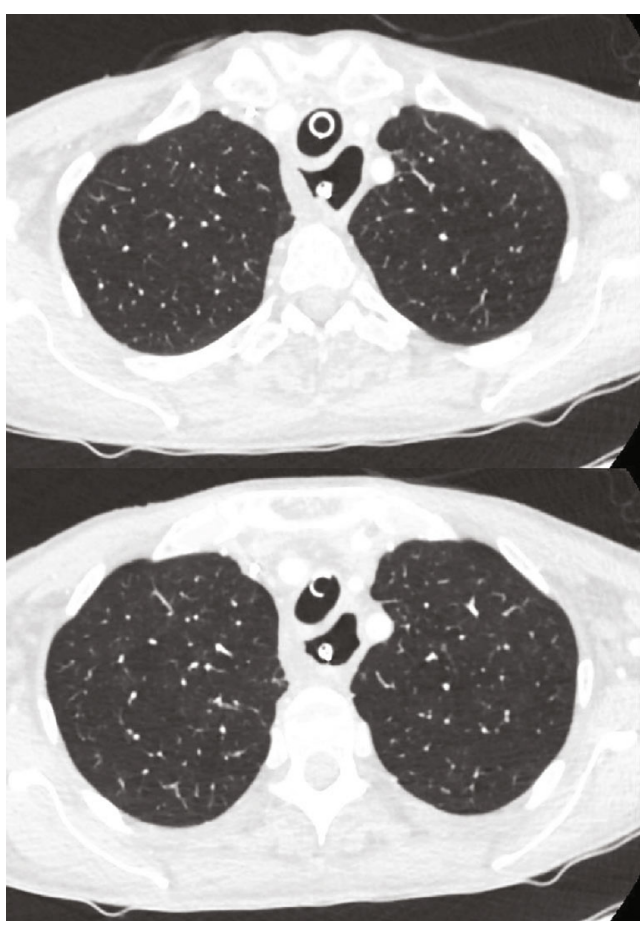

(a)

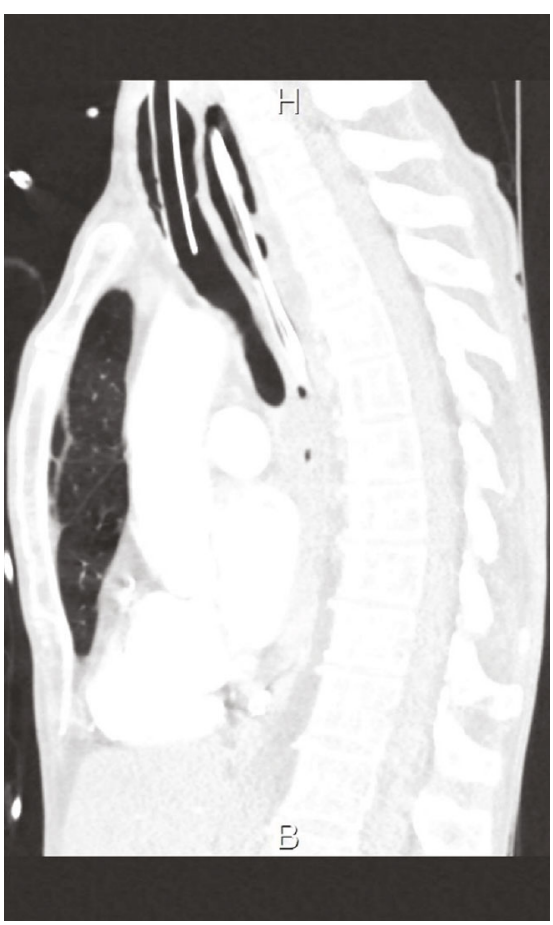

(b)

FIGURE 1: CT-chest showing megaesophagus with nasogastric tube and tracheal intubation but no tracheal compression. (a) Axial sections and (b) sagittal section.

by suspicion of inhalation pneumopathy, a bronchoscopy was performed but not finding of foreign bodies. In view of the presence of a pulmonary focus on chest X-ray (Figure 2), diagnosis of aspiration pneumonia was retained. The patient improved and returned home after few weeks.

Three months later, the patient was rehospitalized in a state of acute respiratory distress, once again after a meal. At this time, new CT-chest without intubation found megaesophagus, this time with tracheal compression (Figure 3). Bronchoscopy performed at this time revealed a TM with complete expiratory collapse and $80 \%$ inspiratory collapse associated with an inflammatory mucosa (Figure 4).

In view of all these elements, we have retained the diagnosis of acute airway obstruction and cardiopulmonary arrest due to TM caused by megaesophagus compression secondary to achalasia. Achalasia was subsequently confirmed by esophageal manometry. No other cause of TM, in particular, no arguments for systemic infection or collagen vascular disease, was highlighted on various examinations. Please note that the patient's giant cell arteritis was perfectly controlled during these respiratory episodes.

On therapeutic plan, in front of patient advanced age and history of myelodysplasia with severe pancytopenia, surgery was not proposed. We proposed intraesophageal botulinum toxin injections under endoscopy to try to treat achalasia. The best treatment for TM is that of the cause. Following this treatment, the patient has not presented any cardiopulmonary arrest but she continued to have repeated lung infections. Unfortunately, she died two years later from a complicated lung infection.

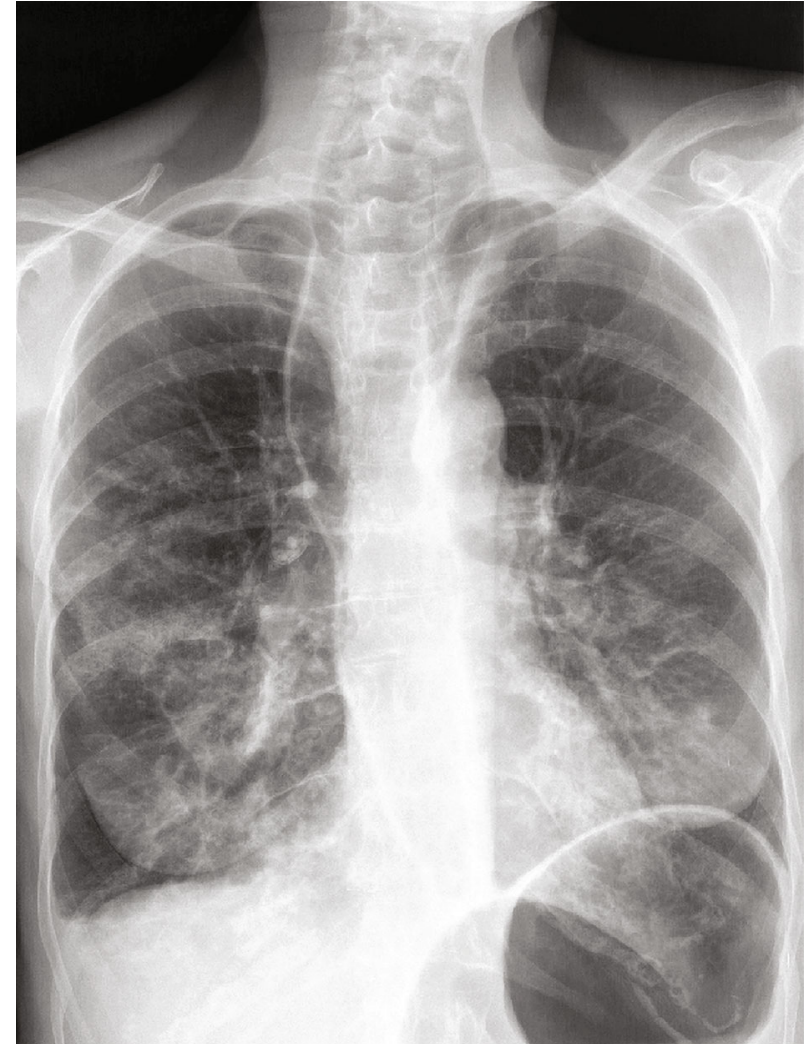

FIgURe 2: Anteroposterior chest X-ray showing enlargement of the upper mediastinum secondary to megaesophagus. 


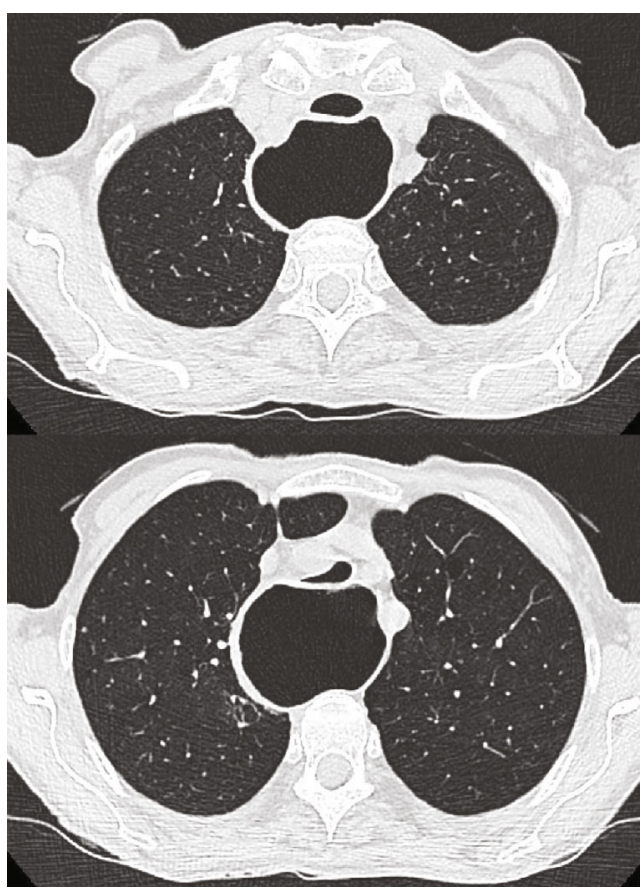

(a)

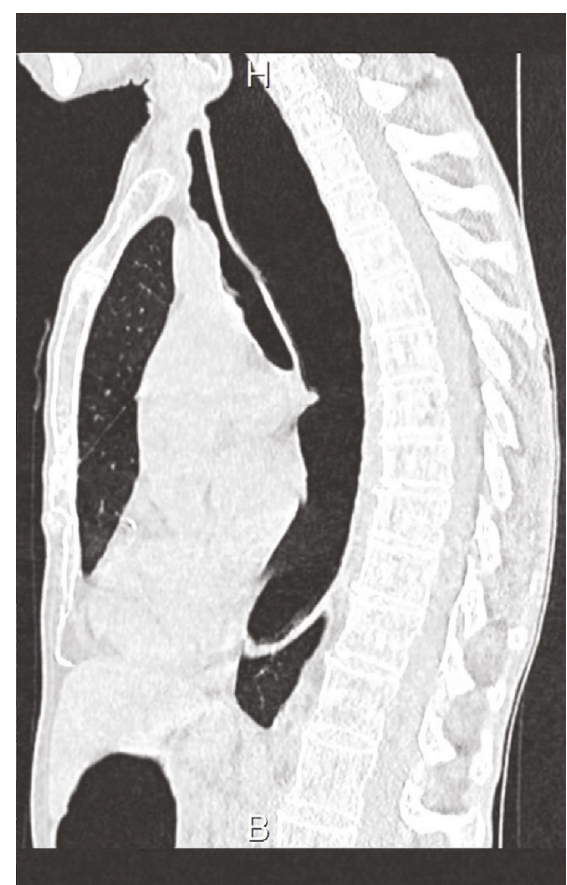

(b)

Figure 3: CT-chest showing megaesophagus with tracheal compression. (a) Axial sections and (b) sagittal section.

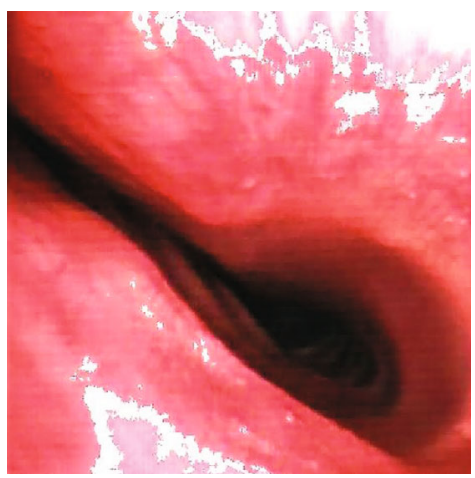

(a)

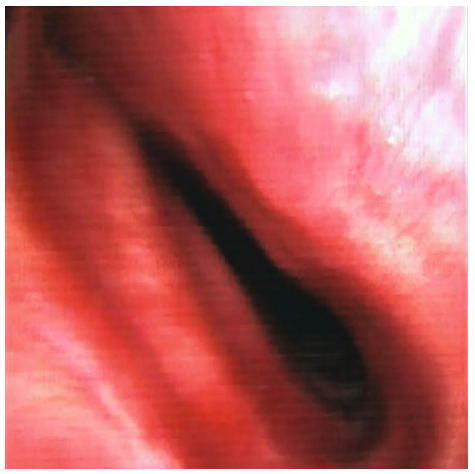

(b)

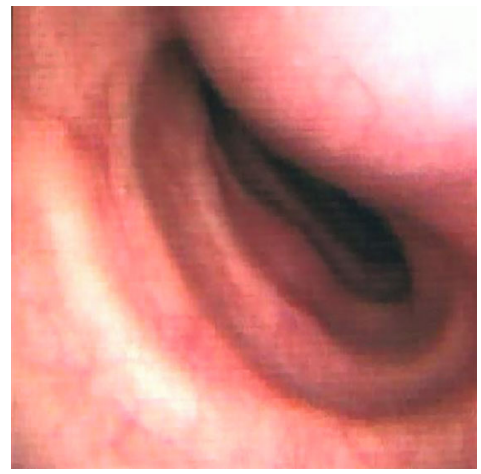

(c)

FIGURE 4: Trachea during bronchoscopic examination. (a) During expiration, at $10 \mathrm{~cm}$ from vocal cords with complete expiratory collapse. (b) During inspiration, at $10 \mathrm{~cm}$ from vocal cords with $80 \%$ inspiratory collapse. (c) Appearance of the trachea at the beginning of the tracheomalacia zone.

\section{Discussion}

Bello et al. [11] first reported acute airway obstruction caused by achalasia in 1950 . To date, approximately 40 such cases have been described. However, to our knowledge, only three cases of TM caused by megaesophagus compression secondary to achalasia [12-14] and a single case of cardiopulmonary arrest secondary to achalasia [15] have been described. Nevertheless, we can assume that cases of TM have been underestimated because in most cases of tracheal compression published, no bronchoscopy was carried out.

Acquired adult TM has many etiologies but is commonly idiopathic, posttraumatic, or secondary to chronic inflammation from recurrent infection and often presents in later life
[16]. Symptoms may not be present until late in the disease process when degeneration of the tracheal cartilages is advanced. Presentation can often be confused with symptomatic asthma, and presentation is even more confusing by concomitant achalasia. Airway collapse results in changes in transtracheal pressure gradients that cannot be compensated by the weakened tracheal wall.

There are no well-defined recommendations for treatment of TM. Asymptomatic patients, in whom diagnosis of TM is fortuitously established, do not require treatment. In symptomatic patients, the first treatment is that of the cause. It is then possible to provide continuous positive airway pressure, tracheal prosthesis, laser treatment, or surgical management. 


\section{Conflicts of Interest}

The authors declare no conflict of interest.

\section{References}

[1] S. Ikeda, T. Hanawa, T. Konishi et al., "Diagnosis, incidence, clinicopathology and surgical treatment of acquired tracheobronchomalacia," Nihon Kyōbu Shikkan Gakkai zasshi, vol. 30, no. 6, pp. 1028-1035, 1992.

[2] K. Jokinen, T. Palva, and J. Nuutinen, "Chronic bronchitis," ORL, vol. 38, no. 3, pp. 178-186, 1976.

[3] K. A. Carden, P. M. Boiselle, D. A. Waltz, and A. Ernst, "Tracheomalacia and tracheobronchomalacia in children and adults: an in-depth review," Chest Journal, vol. 127, no. 3, pp. 984-1005, 2005.

[4] A. Ernst, A. Majid, D. Feller-Kopman et al., "Airway stabilization with silicone stents for treating adult tracheobronchomalacia: a prospective observational study," Chest Journal, vol. 132, no. 2, pp. 609-616, 2007.

[5] S. Cohen, "Motor disorders of the esophagus," New England Journal of Medicine, vol. 301, no. 4, pp. 184-192, 1979.

[6] W. Park and M. F. Vaezi, "Etiology and pathogenesis of achalasia: the current understanding," The American Journal of Gastroenterology, vol. 100, no. 6, pp. 1404-1414, 2005.

[7] O. M. O'Neill, B. T. Johnston, and H. G. Coleman, "Achalasia: a review of clinical diagnosis, epidemiology, treatment and outcomes," World Journal of Gastroenterology, vol. 19, no. 35, pp. 5806-5812, 2013.

[8] D. C. Sadowski, F. Ackah, B. Jiang, and L. W. Svenson, "Achalasia: incidence, prevalence and survival. A population-based study," Neurogastroenterology \& Motility, vol. 22, no. 9, pp. e256-e261, 2010.

[9] P. Kumar and M. Clark, Clinical Medicine, WB Saunders, Edinburgh, 4th edition, 1998.

[10] D. Pohl and R. Tutuian, "Achalasia: an overview of diagnosis and treatment," Journal of Gastrointestinal and Liver Diseases, vol. 16, no. 3, pp. 297-303, 2007.

[11] C. T. Bello, J. R. Lewin, and F. G. E. CM Norris Jr., "Achalasia (cardiospasm): report of a case with extreme and unusual manifestations," Annals of Internal Medicine, vol. 32, no. 6, pp. 1184-1190, 1950.

[12] C. De Pieri, P. Cogo, and A. Barbato, "Tracheomalacia due to esophageal achalasia," Archivos de Bronconeumología, vol. 53, no. 2, pp. 78-79, 2017.

[13] J. H. Atkins, J. E. Mandel, and D. C. Metz, "Sudden tracheal collapse during EGD and subsequent anesthetic management with dexmedetomidine-ketamine in a patient with achalasia and tracheomalacia," Case reports in anesthesiology, vol. 2011, Article ID 281679, 4 pages, 2011.

[14] J. G. Barr, H. Dean, and G. Morrison, "A rare case of paediatric stridor caused by achalasia," The Journal of Laryngology \& Otology, vol. 129, no. 7, pp. 725-726, 2015.

[15] T. Hifumi, I. Okada, J. Inoue, and Y. Koido, "Cardiopulmonary arrest owing to oesophageal achalasia recovered completely with cardiopulmonary resuscitation followed by therapeutic hypothermia," BMJ Case Reports, vol. 2013, 2013.

[16] H. Dutau, S. Laroumagne, O. Bylicki, T. Vandemoortele, and P. Astoul, "Trachéobronchomalacie de l'adulte : avancées et controverses," Revue des Maladies Respiratoires, vol. 29, no. 10, pp. 1198-1208, 2012. 